\title{
Effects of Side-Chain Spacing and Length on Hydration States of the Poly(2-methoxyethyl acrylate) Analogs: A Molecular Dynamics Study
}

\author{
An-Tsung Kuo ${ }^{1 *}$, Shingo Urata ${ }^{1}$, Ryohei Koguchi ${ }^{2}$, Toshiki Sonoda ${ }^{3}$, \\ Shingo Kobayashi ${ }^{3}$ and Masaru Tanaka ${ }^{3}$
}

\footnotetext{
${ }^{1}$ Innovative Technology Laboratories, AGC Inc., Yokohama 230-0045, Japan

${ }^{2}$ Materials Integration Laboratories, AGC Inc., Yokohama 230-0045, Japan

${ }^{3}$ Institute for Materials Chemistry and Engineering, Kyushu University, Fukuoka 819-0395, Japan
}

*Corresponding author. Tel: (+) 81-50-9014-1394. Fax: (+) 81-45-374-8856.

Email: antsung.kuo@agc.com 


\section{Supporting Information}

\section{S1. Simulation analysis}

A time autocorrelation function, $C_{i j}(t)$, is evaluated to investigate the dynamics behavior of the BW varying to the NBW. The time autocorrelation function is calculated as

$$
C_{i j}(t)=\frac{\left\langle h_{j}(t) h_{i}(0)\right\rangle}{\left\langle h_{i}(0) h_{i}(0)\right\rangle},
$$

where angular brackets denote ensemble average. The subscripts $i$ and $j$ refer to the BW2, BW1 and NBW. The value for $h_{i}(t)$ is 1 or 0 when a water molecule belongs to $i$ state or not, respectively. The time autocorrelation function is expected to increase from 0 to 1 as time progresses in response to the change of water from BW to NBW. The orientational autocorrelation function, $C_{s}(t)$, is calculated to describe the side-chain flexibility of the polymer.

$$
C_{s}(t)=\langle n(0) \cdot n(t)\rangle
$$

where $n(t)$ is a unit vector of the side-chain from the attached main-chain carbon to the end of the side-chain carbon. To have a quantitative comparison among the polymers, the $C_{i j}(t)$ and $C_{s}(t)$ are fitted to the Kohlrausch-Williams-Watts (KWW) function to obtain the relaxation time, $\tau .^{1}$

$$
f_{\beta}(t)=\exp \left[-(t / \tau)^{\beta}\right], \quad(0<\beta \leq 1)
$$

where $\beta$ is a KWW exponent. 
Table S1. The compositions of the hydrated systems. Each system includes 20 polymer chains, respectively.

\begin{tabular}{|c|c|c|c|c|c|c|c|c|c|c|c|}
\hline \multicolumn{3}{|c|}{ HP2 (50mer) } & \multicolumn{3}{|c|}{ HP2 (100mer) } & \multicolumn{3}{|c|}{ HP4 } & \multicolumn{3}{|c|}{ HP5 } \\
\hline \multicolumn{2}{|c|}{$\mathrm{H}_{2} \mathrm{O}$ content } & \multirow{2}{*}{$\mathrm{H}_{2} \mathrm{O}$} & \multicolumn{2}{|c|}{$\mathrm{H}_{2} \mathrm{O}$ content } & \multirow{2}{*}{$\mathrm{H}_{2} \mathrm{O}$} & \multicolumn{2}{|c|}{$\mathrm{H}_{2} \mathrm{O}$ content } & \multirow{2}{*}{$\mathrm{H}_{2} \mathrm{O}$} & \multicolumn{2}{|c|}{$\mathrm{H}_{2} \mathrm{O}$ content } & \multirow{2}{*}{$\mathrm{H}_{2} \mathrm{O}$} \\
\hline $\mathrm{wt} \%$ & $\mathrm{H}_{2} \mathrm{O} /$ mer & & $\mathrm{wt} \%$ & $\mathrm{H}_{2} \mathrm{O} /$ mer & & $\mathrm{wt} \%$ & $\mathrm{H}_{2} \mathrm{O} /$ mer & & $\mathrm{wt} \%$ & $\mathrm{H}_{2} \mathrm{O} / \mathrm{mer}$ & \\
\hline 1.0 & 0.074 & 74 & 1.0 & 0.074 & 144 & 0.6 & 0.05 & 50 & 0.5 & 0.05 & 50 \\
\hline 3.0 & 0.224 & 224 & 3.0 & 0.224 & 448 & 1.1 & 0.1 & 100 & 1.0 & 0.1 & 100 \\
\hline 5.0 & 0.38 & 380 & 5.0 & 0.38 & 770 & 2.2 & 0.2 & 200 & 2.0 & 0.2 & 200 \\
\hline 7.0 & 0.545 & 545 & 7.0 & 0.545 & 1090 & 3.3 & 0.3 & 300 & 3.0 & 0.3 & 300 \\
\hline 9.0 & 0.715 & 715 & 9.0 & 0.715 & 1430 & 4.4 & 0.4 & 400 & 4.0 & 0.4 & 400 \\
\hline 10.5 & 0.848 & 848 & 10.5 & 0.848 & 1696 & 5.4 & 0.5 & 500 & 5.0 & 0.5 & 500 \\
\hline 12.0 & 0.986 & 986 & 12.0 & 0.986 & 1972 & 7.4 & 0.7 & 700 & 6.8 & 0.7 & 700 \\
\hline 13.5 & 1.128 & 1128 & 13.5 & 1.128 & 2256 & 9.3 & 0.9 & 900 & 8.6 & 0.9 & 900 \\
\hline 15.0 & 1.275 & 1275 & 15.0 & 1.275 & 2550 & 11.1 & 1.1 & 1100 & 10.3 & 1.1 & 1100 \\
\hline 16.5 & 1.428 & 1428 & 16.5 & 1.428 & 2856 & 11.7 & 1.163 & 1163 & 12.0 & 1.3 & 1300 \\
\hline 17.2 & 1.5 & 1500 & 17.2 & 1.5 & 3000 & 12.9 & 1.3 & 1300 & 13.6 & 1.5 & 1500 \\
\hline 18.0 & 1.586 & 1586 & 18.0 & 1.586 & 3172 & 14.6 & 1.5 & 1500 & 14.4 & 1.608 & 1608 \\
\hline 20.0 & 1.806 & 1806 & 20.0 & 1.806 & 3612 & 16.6 & 1.75 & 1750 & 15.5 & 1.75 & 1750 \\
\hline 22.0 & 2.038 & 2038 & 22.0 & 2.038 & 4076 & 18.6 & 2 & 2000 & 17.3 & 2 & 2000 \\
\hline & & & & & & 20.4 & 2.25 & 2250 & 19.1 & 2.25 & 2250 \\
\hline & & & & & & & & & 20.7 & 2.5 & 2500 \\
\hline
\end{tabular}

\begin{tabular}{|c|c|c|c|c|c|c|c|c|c|c|c|}
\hline \multicolumn{3}{|c|}{ HP7 } & \multicolumn{3}{|c|}{ HP8 } & \multicolumn{3}{|c|}{ PMC4A } & \multicolumn{3}{|c|}{ PMC5A } \\
\hline \multicolumn{2}{|c|}{$\mathrm{H}_{2} \mathrm{O}$ content } & \multirow{2}{*}{$\mathrm{H}_{2} \mathrm{O}$} & \multicolumn{2}{|c|}{$\mathrm{H}_{2} \mathrm{O}$ content } & \multirow{2}{*}{$\mathrm{H}_{2} \mathrm{O}$} & \multicolumn{2}{|c|}{$\mathrm{H}_{2} \mathrm{O}$ content } & \multirow{2}{*}{$\mathrm{H}_{2} \mathrm{O}$} & \multicolumn{2}{|c|}{$\mathrm{H}_{2} \mathrm{O}$ content } & \multirow{2}{*}{$\mathrm{H}_{2} \mathrm{O}$} \\
\hline $\mathrm{wt} \%$ & $\mathrm{H}_{2} \mathrm{O} / \mathrm{mer}$ & & $\mathrm{wt} \%$ & $\mathrm{H}_{2} \mathrm{O} / \mathrm{mer}$ & & $w t \%$ & $\mathrm{H}_{2} \mathrm{O} /$ mer & & $w t \%$ & $\mathrm{H}_{2} \mathrm{O} / \mathrm{mer}$ & \\
\hline 0.4 & 0.05 & 50 & 0.4 & 0.05 & 50 & 0.6 & 0.05 & 50 & 0.5 & 0.05 & 50 \\
\hline 0.9 & 0.1 & 100 & 0.8 & 0.1 & 100 & 1.1 & 0.1 & 100 & 1.0 & 0.1 & 100 \\
\hline 1.8 & 0.2 & 200 & 1.7 & 0.2 & 200 & 2.2 & 0.2 & 200 & 2.0 & 0.2 & 200 \\
\hline 2.6 & 0.3 & 300 & 2.5 & 0.3 & 300 & 3.3 & 0.3 & 300 & 2.5 & 0.25 & 250 \\
\hline 3.5 & 0.4 & 400 & 3.3 & 0.4 & 400 & 4.4 & 0.4 & 400 & 3.0 & 0.3 & 300 \\
\hline 4.3 & 0.5 & 500 & 4.0 & 0.5 & 500 & 5.1 & 0.472 & 472 & 3.5 & 0.35 & 350 \\
\hline 5.9 & 0.7 & 700 & 5.6 & 0.7 & 700 & 5.4 & 0.5 & 500 & 4.0 & 0.4 & 400 \\
\hline 6.7 & 0.8 & 800 & 7.0 & 0.9 & 900 & 6.4 & 0.6 & 600 & 5.0 & 0.5 & 500 \\
\hline 7.5 & 0.9 & 900 & 7.8 & 1 & 1000 & 7.4 & 0.7 & 700 & 5.9 & 0.6 & 600 \\
\hline 8.3 & 1 & 1000 & 8.3 & 1.076 & 1076 & 9.3 & 0.9 & 900 & 6.8 & 0.7 & 700 \\
\hline 9.0 & 1.1 & 1100 & 8.5 & 1.1 & 1100 & 11.1 & 1.1 & 1100 & 8.6 & 0.9 & 900 \\
\hline 10.5 & 1.3 & 1300 & 9.9 & 1.3 & 1300 & 12.9 & 1.3 & 1300 & 10.3 & 1.1 & 1100 \\
\hline 11.9 & 1.5 & 1500 & 11.2 & 1.5 & 1500 & 14.6 & 1.5 & 1500 & 12.0 & 1.3 & 1300 \\
\hline 13.6 & 1.75 & 1750 & 12.8 & 1.75 & 1750 & 16.6 & 1.75 & 1750 & 13.6 & 1.5 & 1500 \\
\hline 15.3 & 2 & 2000 & 14.4 & 2 & 2000 & 18.6 & 2 & 2000 & 15.5 & 1.75 & 1750 \\
\hline & & & & & & & & & 17.3 & 2 & 2000 \\
\hline
\end{tabular}




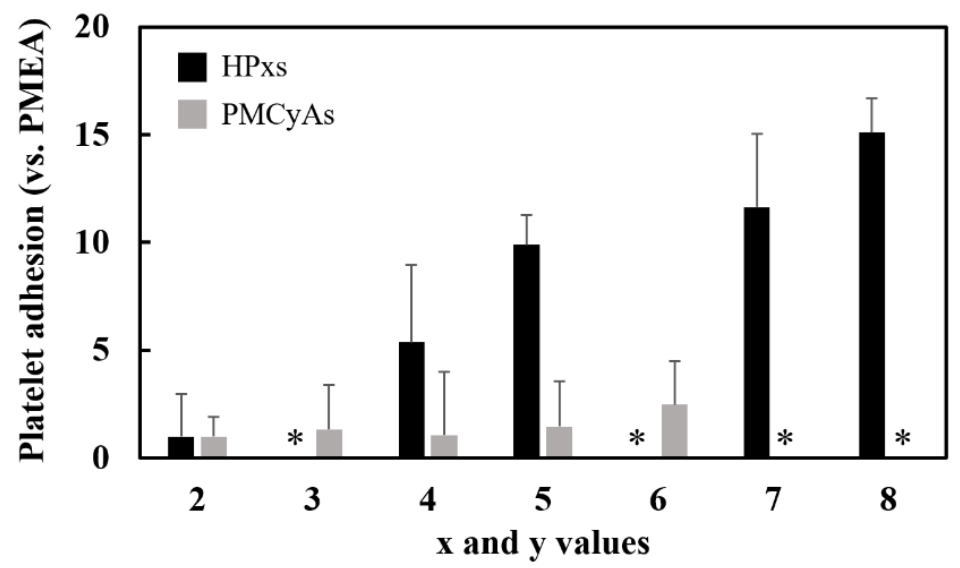

Figure S1. Results of the platelet adhesion test. The number of adhered platelets was normalized relative to that of PMEA. The data of HPxs and PMCyAs were taken from Refs. 2 and 3 respectively. ${ }^{2-3}$ The symbol " * " denotes that the platelet adhesion test was not performed.
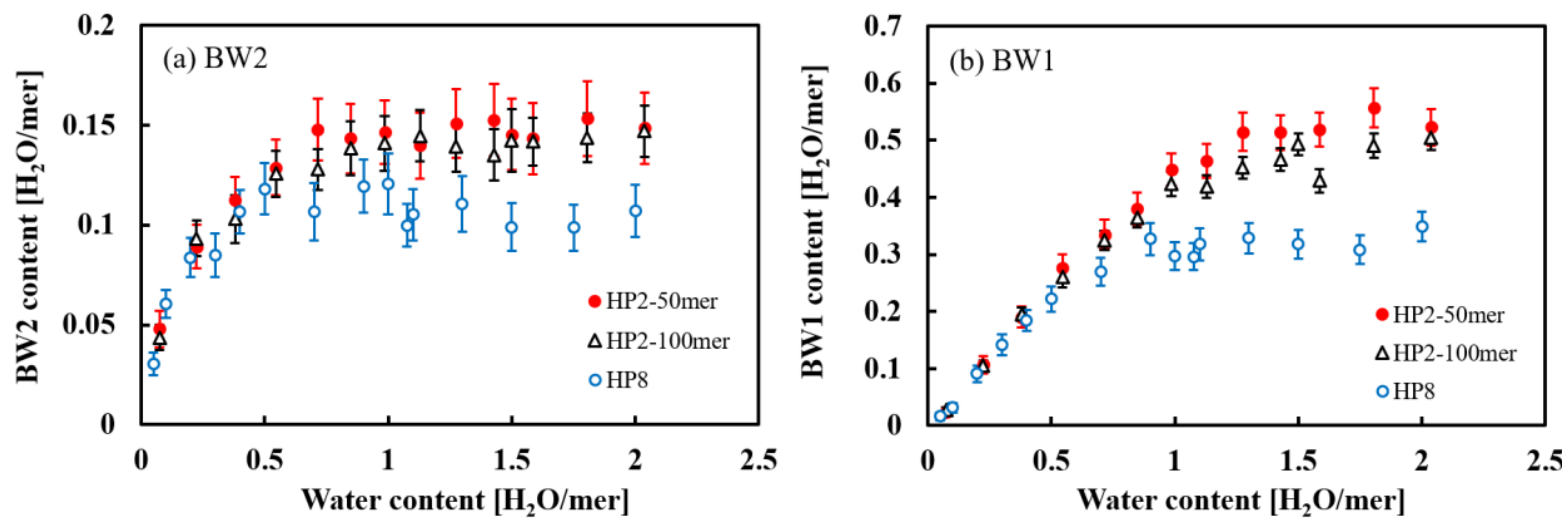

Figure S2. Amounts of (a) BW2 and (b) BW1 in the hydrated HP2 and HP8 as a function of water content. HP2-50mer and HP2-100mer denote HP2 composed of 50 and 100 monomer unit, respectively. Molecular weight: 6502 for HP2-50mer, 13002 for HP2-100mer, and 10702 for HP8. 

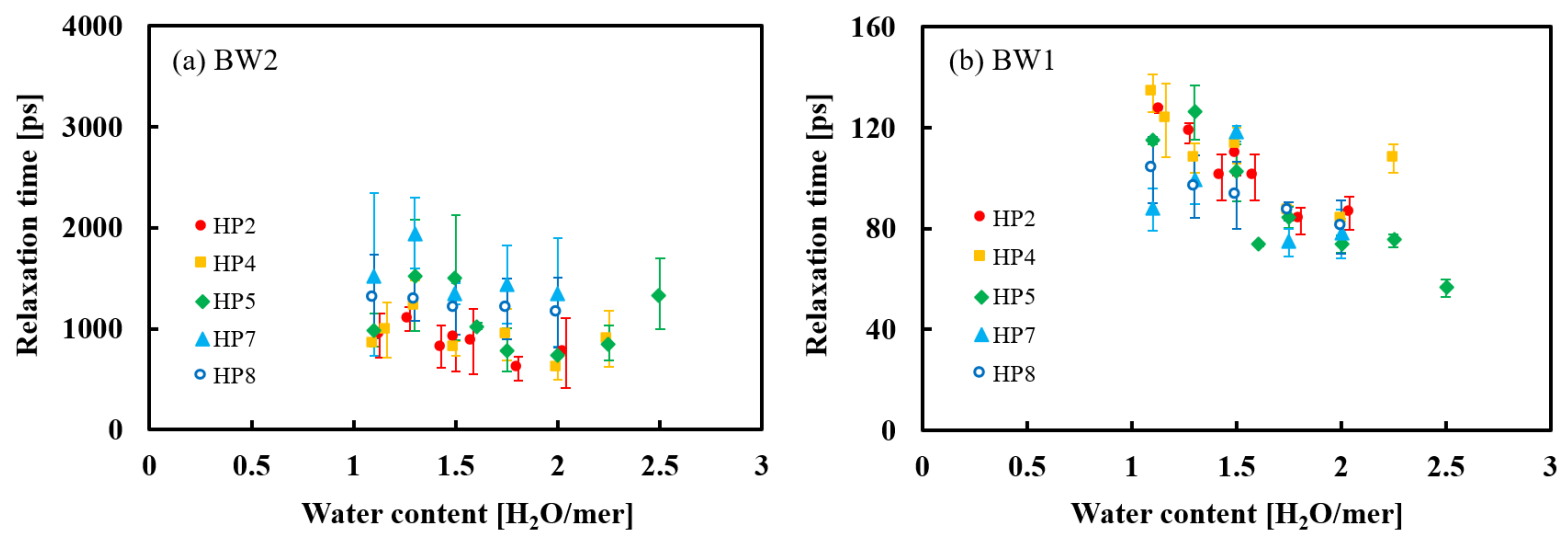

Figure S3. KWW relaxation times of (a) BW2 and (b) BW1 varying to NBW in the hydrated HPx as a function of water content. 

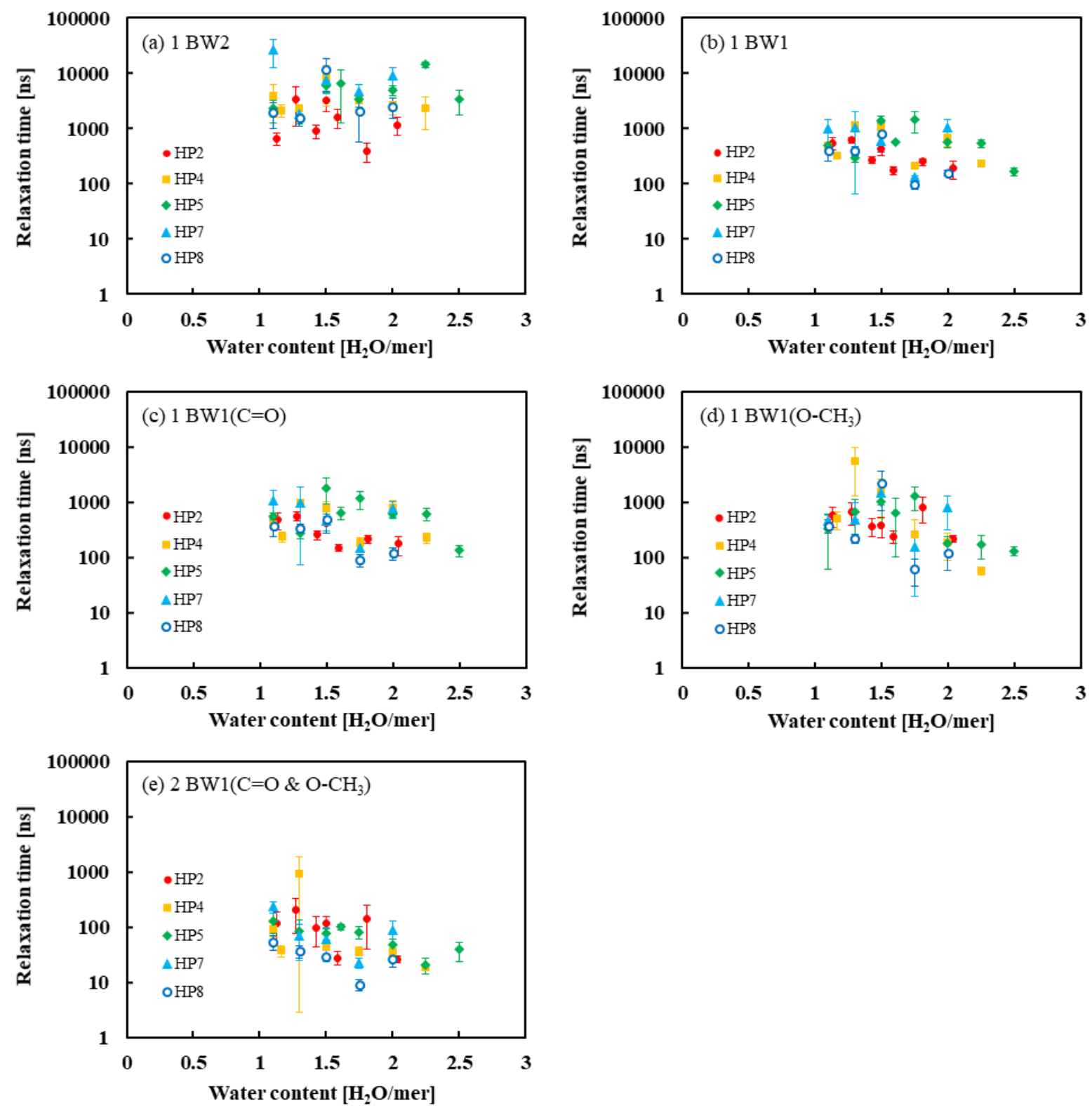

Figure S4. The orientational relaxation time of HPx side-chains estimated by using KWW function as a function of water content. The side chains interact with (a) one BW2 molecule, (b) one BW1 molecules, (c) one BW1 $(\mathrm{C}=\mathrm{O})$ molecule, $(\mathrm{d})$ one $\mathrm{BW} 1\left(\mathrm{O}-\mathrm{CH}_{3}\right)$ molecules, and (e) one BW1 $(\mathrm{C}=\mathrm{O}) \&$ one BW1 $\left(\mathrm{O}-\mathrm{CH}_{3}\right)$ molecule. (See Table 1 in the main text for the notations.) 
(a) HP2

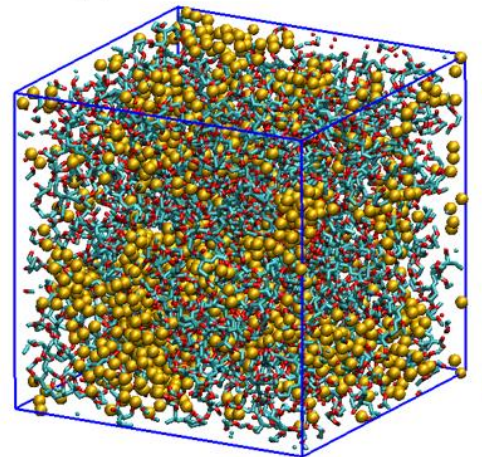

(d) HP7

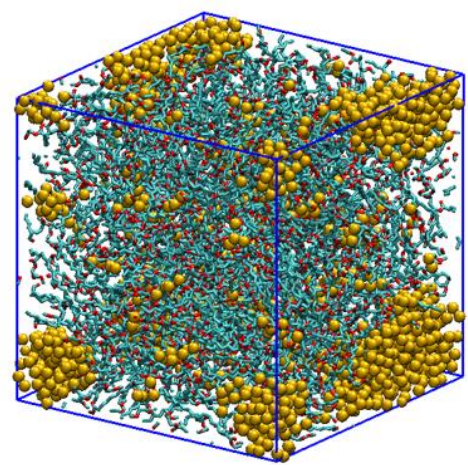

(b) HP4

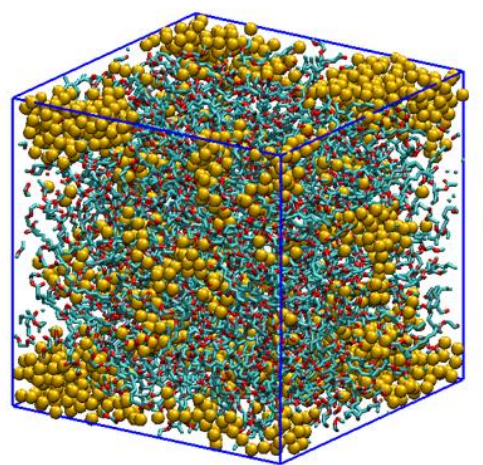

(e) HP8

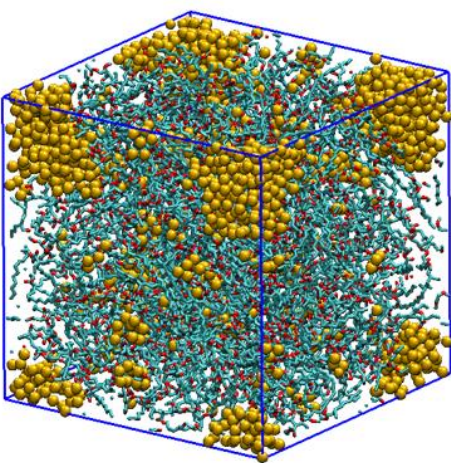

(c) HP5

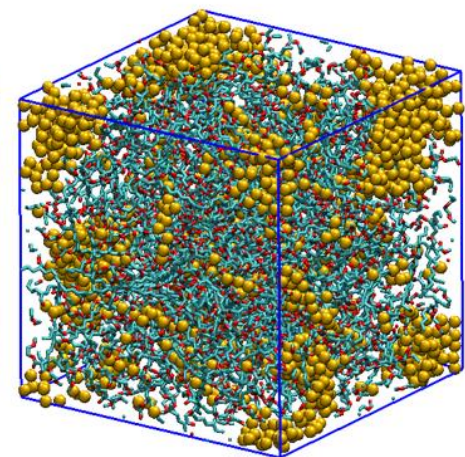

Figure S5. Snapshots of the hydrated HPxs at $1.5 \mathrm{H}_{2} \mathrm{O} /$ mer of the water content: (a) HP2, (b) HP4, (c) HP5, (d) HP7, and (e) HP8. The substances are colored as follows: (cyan) carbon backbone, (red) oxygen of polymer, and (yellow) oxygen of water. H atoms are not shown. 

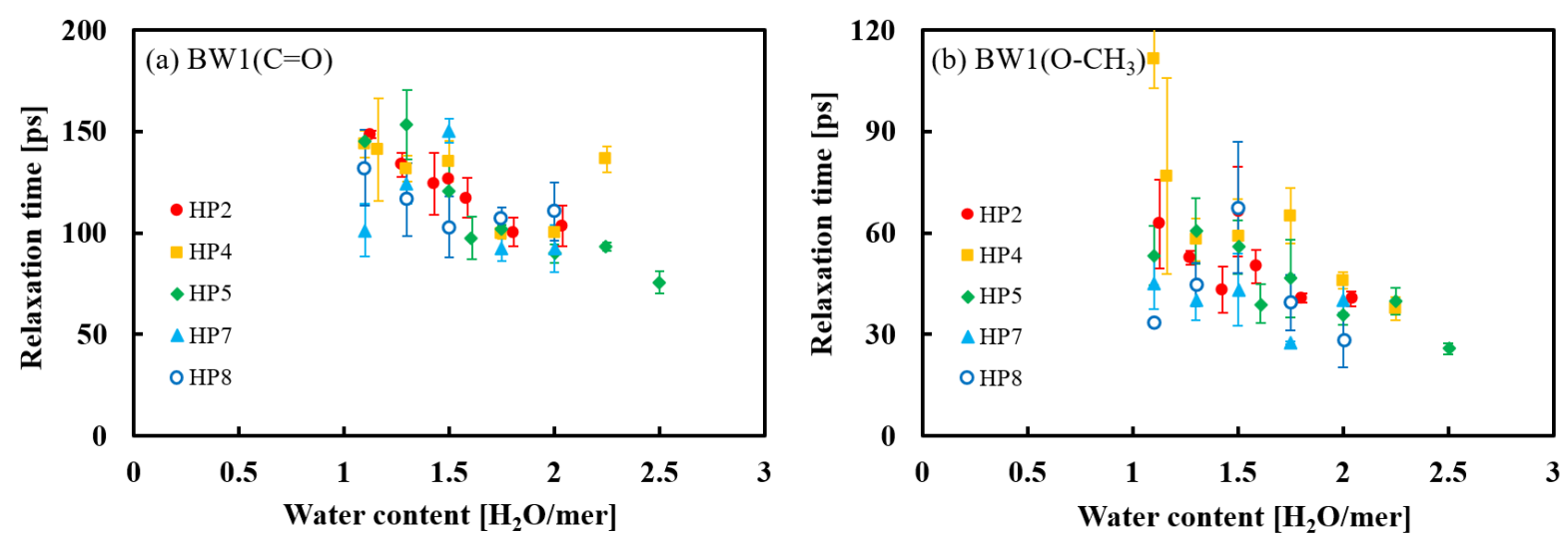

Figure S6. KWW relaxation times of (a) $\mathrm{BW} 1(\mathrm{C}=\mathrm{O})$ and (b) $\mathrm{BW} 1\left(\mathrm{O}-\mathrm{CH}_{3}\right)$ varying to NBW in the hydrated HPx as a function of water content. (See Table 1 in the main text for the notations.)
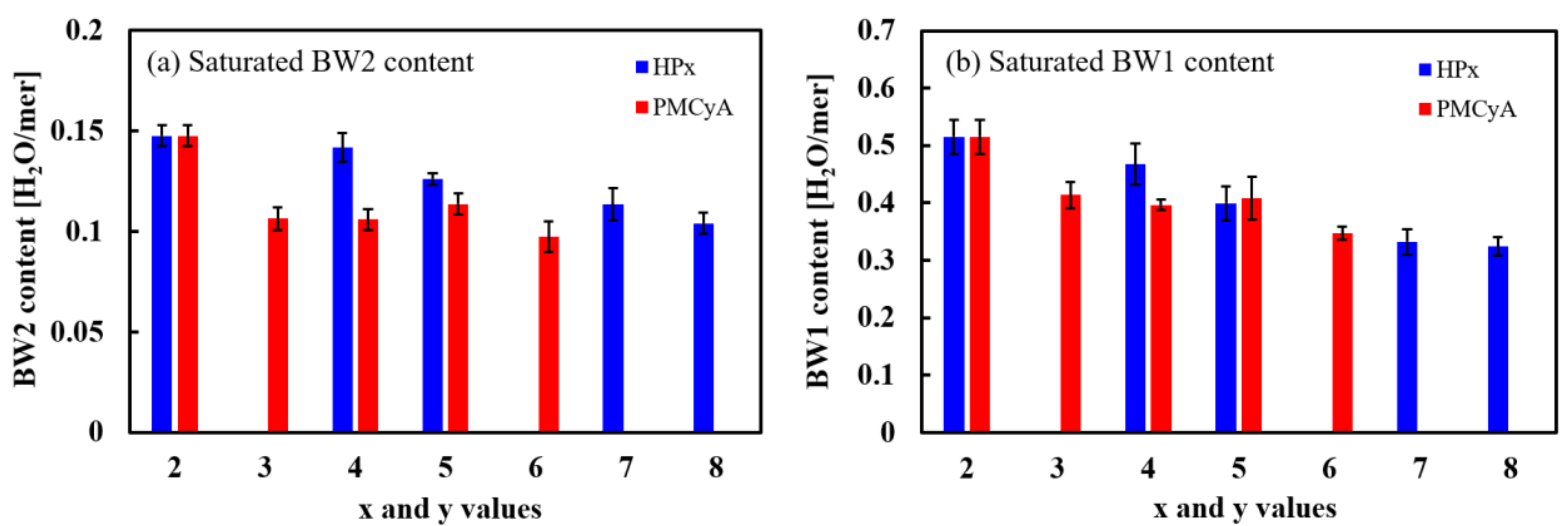

Figure S7. Saturated (a) BW2 and (b) BW1 contents for HPx (x=2, 4, 5, 7, and 8) and PMCyA $(y=2-6)$. The saturated value was taken from the average of BW2 or BW1 contents at water content $\geq 1.1 \mathrm{H}_{2} \mathrm{O} /$ mer. 

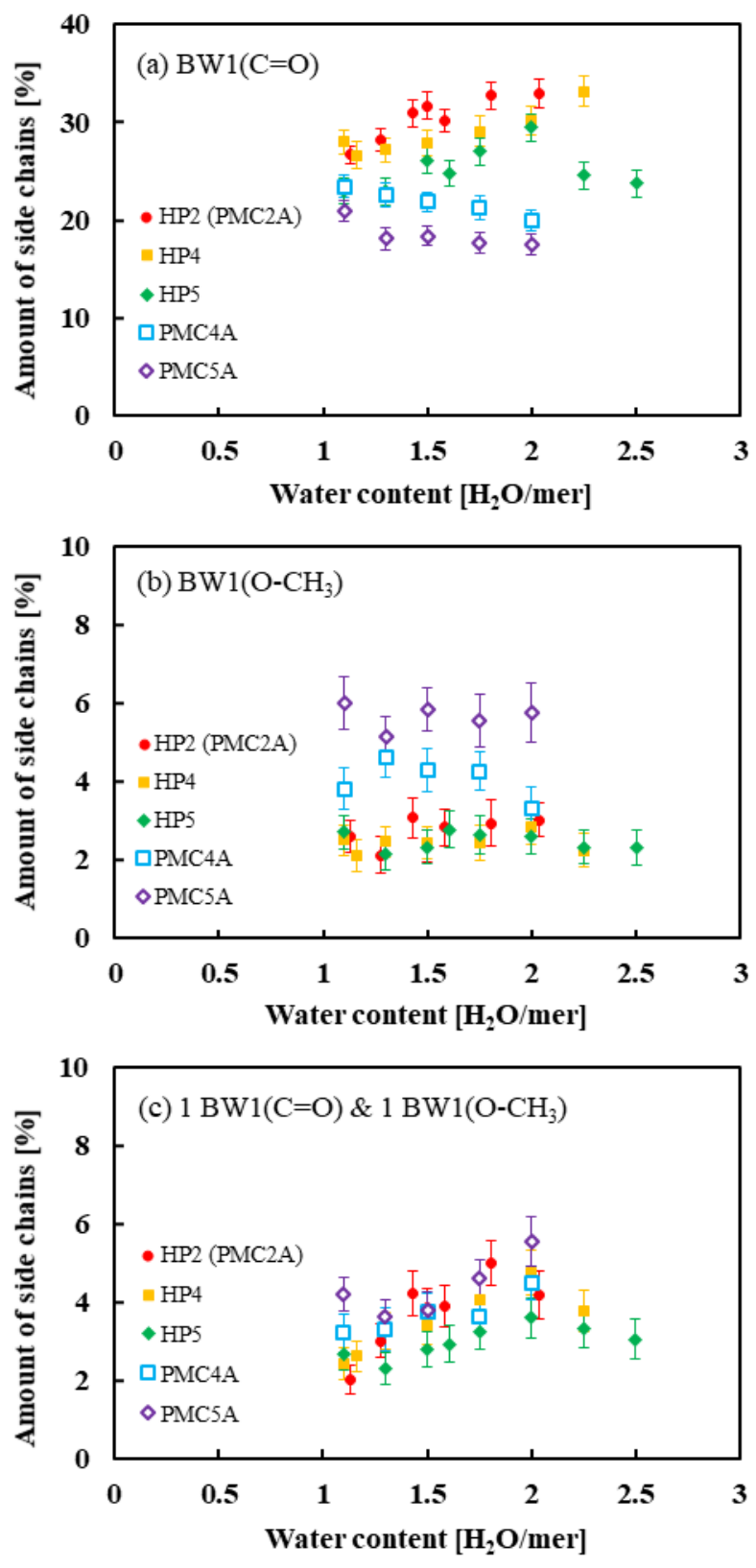

Figure S8. Amounts of side-chains interacting with (a) one $\mathrm{BW} 1(\mathrm{C}=\mathrm{O})$ molecule, (b) one $\mathrm{BW} 1\left(\mathrm{O}-\mathrm{CH}_{3}\right)$ molecule, respectively, and $(\mathrm{c})$ one $\mathrm{BW} 1(\mathrm{C}=\mathrm{O})$ \& one $\mathrm{BW} 1\left(\mathrm{O}-\mathrm{CH}_{3}\right)$ molecules simultaneously for hydrated HPx and PMCyA (x, y = 2, 4 and 5). (See Table 1 for the notations.) 

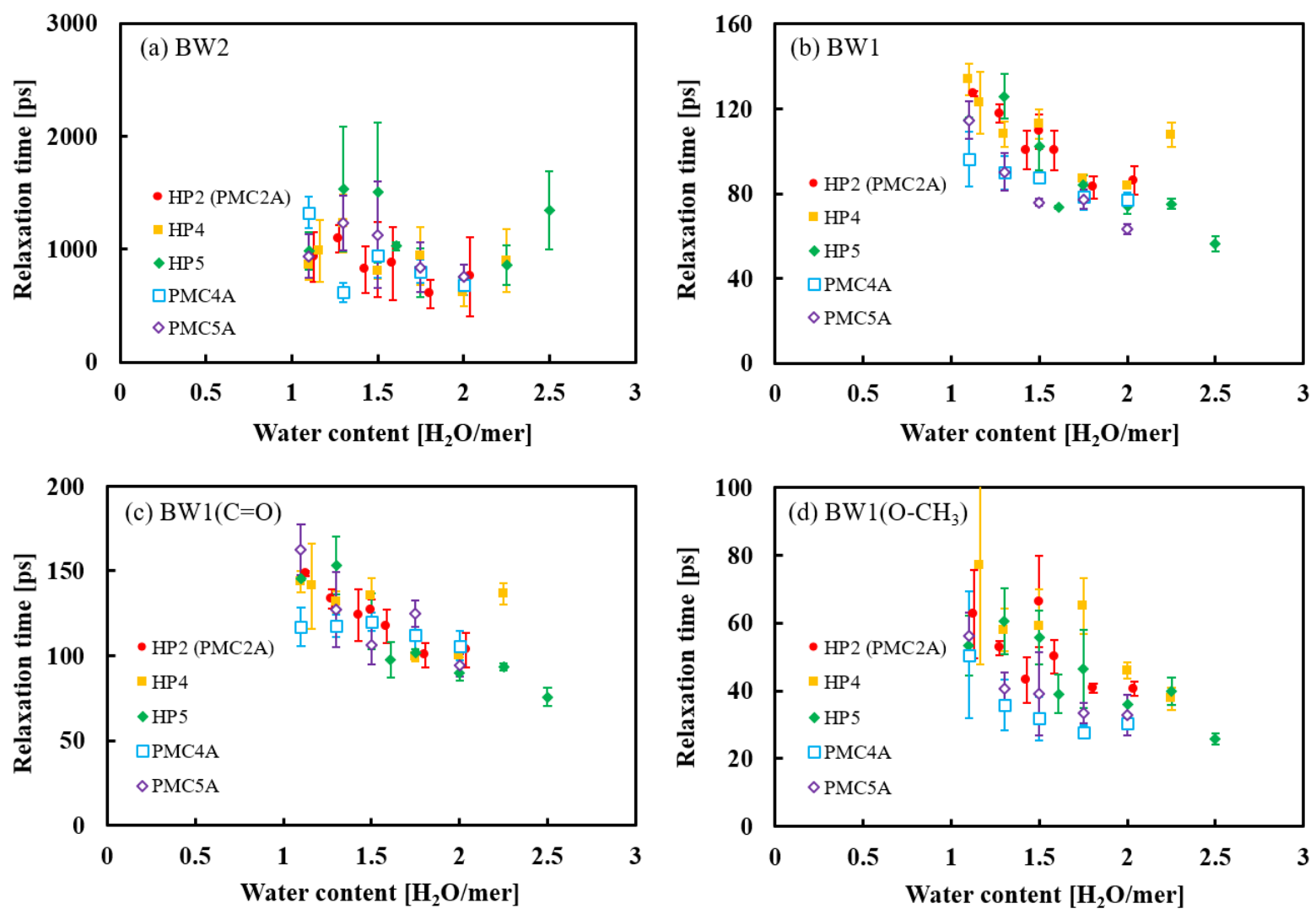

Figure S9. KWW relaxation times of (a) BW2, (b) BW1, (c) BW1(C=O), and (d) BW1(O$\left.\mathrm{CH}_{3}\right)$ varying to NBW in the hydrated HPx and PMCyA (x, y =2, 4 and 5) as a function of water content. 

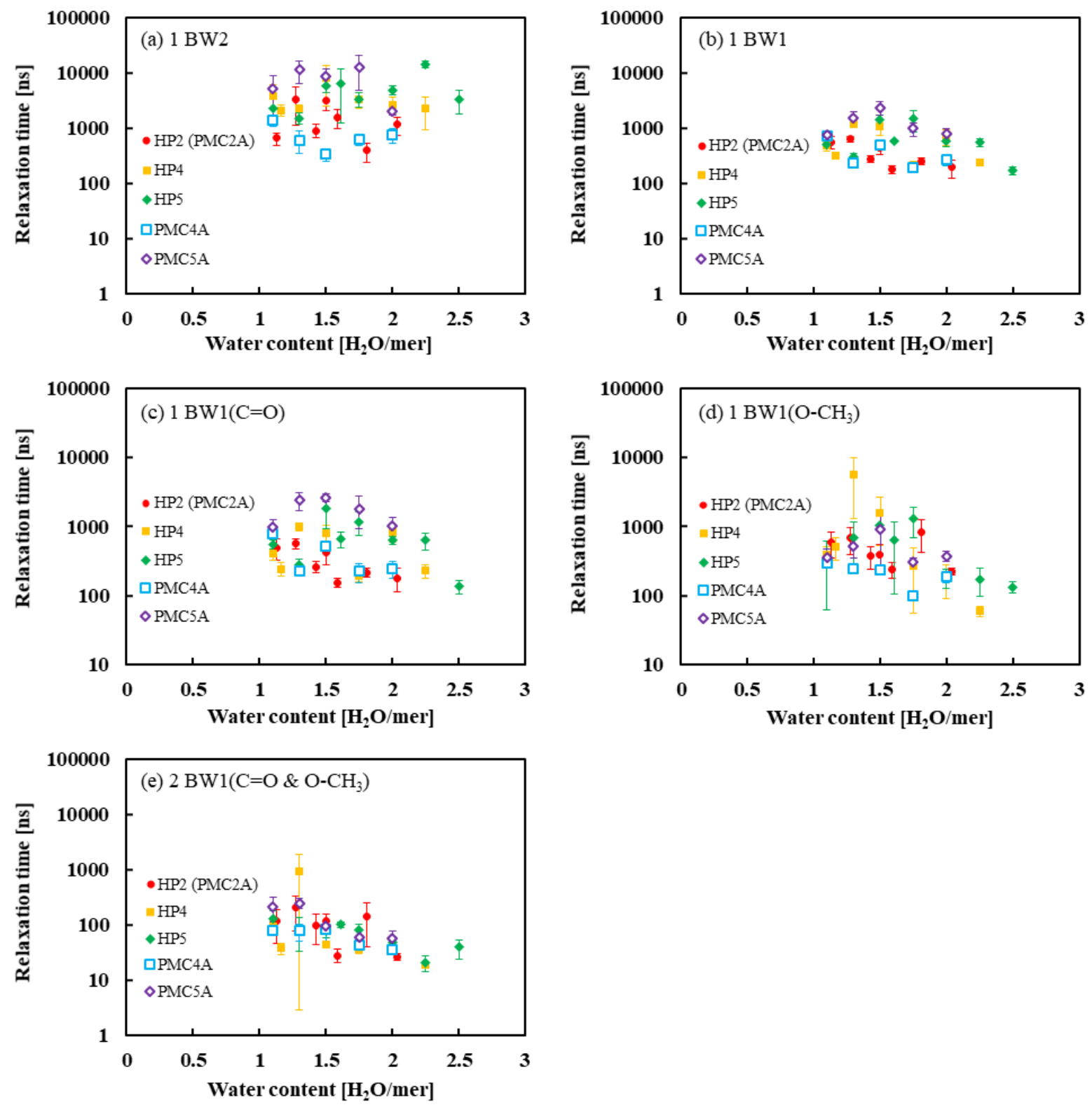

Figure S10. The orientational relaxation time of HPx and PMCyA (x, y =2, 4 and 5) sidechains estimated by using KWW function as a function of water content. The side chains interact with (a) one BW2 molecule, (b) one BW1 molecules, (c) one BW1 $(\mathrm{C}=\mathrm{O})$ molecule, (d) one BW1 $\left(\mathrm{O}-\mathrm{CH}_{3}\right)$ molecules, and $(\mathrm{e})$ one $\mathrm{BW} 1(\mathrm{C}=\mathrm{O})$ \& one BW1 $\left(\mathrm{O}-\mathrm{CH}_{3}\right)$ molecule. (See Table 1 in the main text for the notations.) 

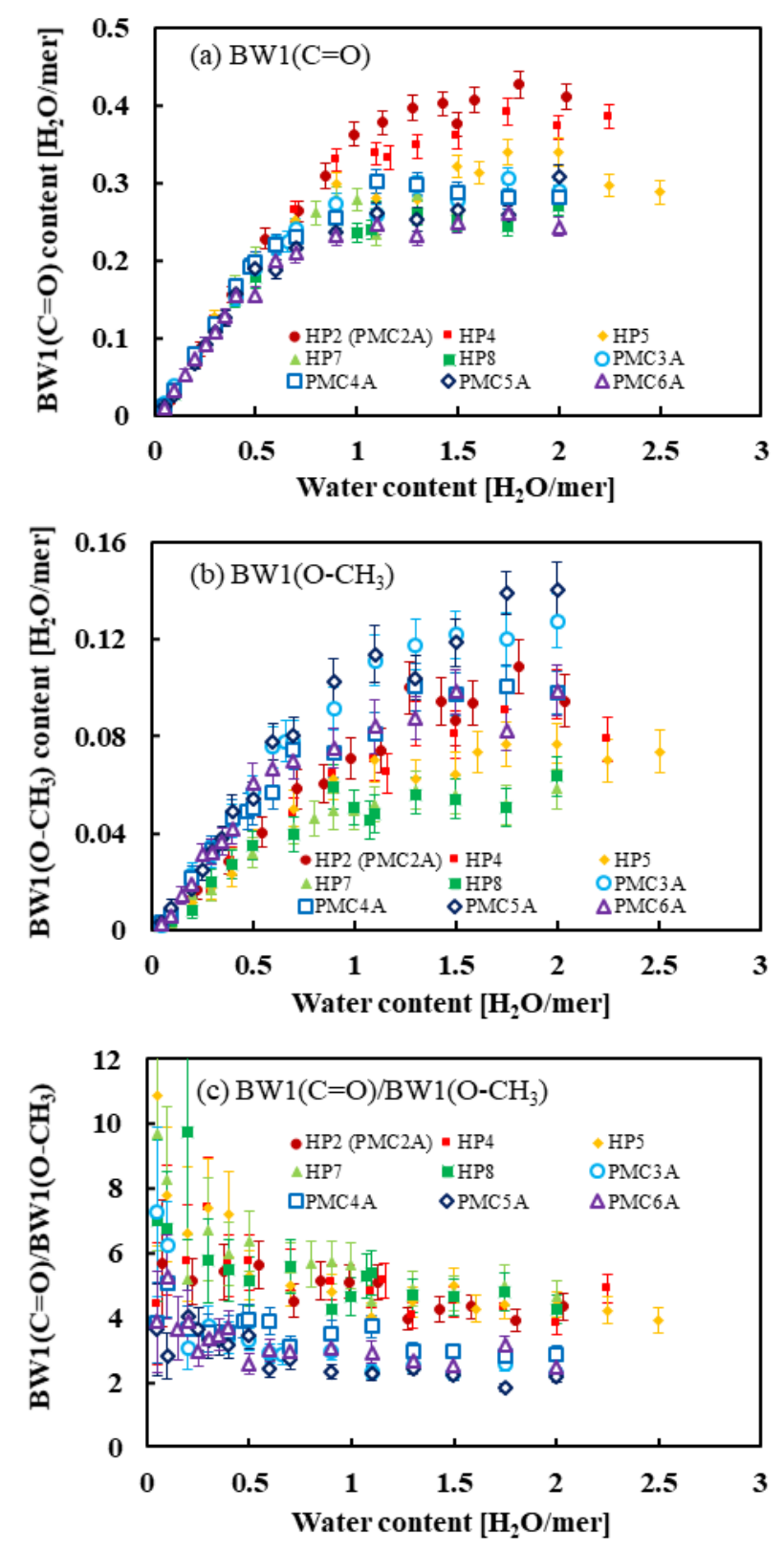

Figure S11. Amounts of (a) BW1 $(\mathrm{C}=\mathrm{O})$ and (b) $\mathrm{BW} 1\left(\mathrm{O}-\mathrm{CH}_{3}\right)$ and $(\mathrm{c})$ the ratio of $\mathrm{BW} 1(\mathrm{C}=\mathrm{O})$ to $\mathrm{BW} 1\left(\mathrm{O}-\mathrm{CH}_{3}\right)$ for all hydrated HPxs and PMCyAs as a function of water content. (See Table 1 for the notations.) 

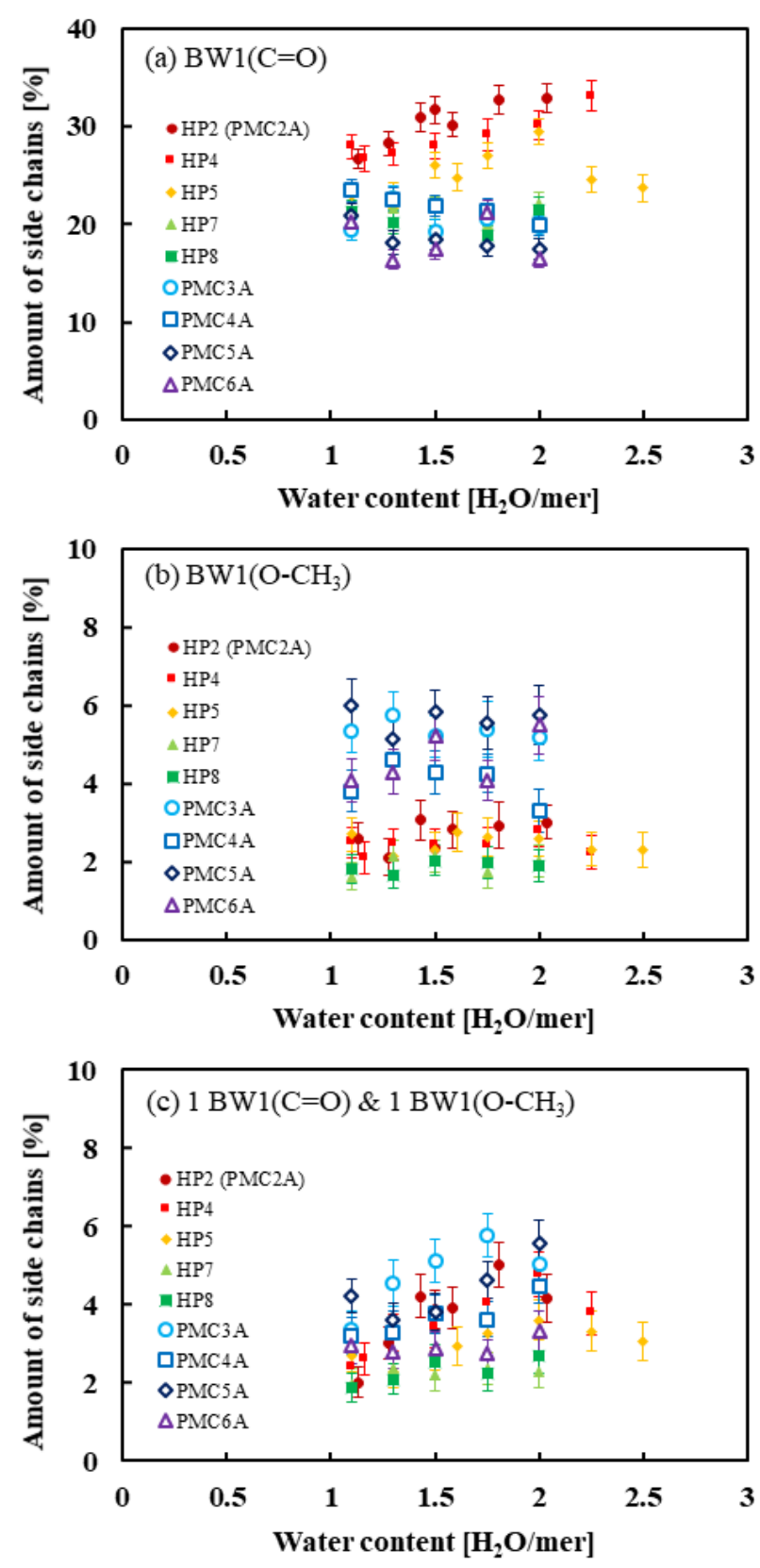

Figure S12. Amounts of side-chains interacting with (a) one $\mathrm{BW} 1(\mathrm{C}=\mathrm{O})$ molecule, $(\mathrm{b})$ one $\mathrm{BW} 1\left(\mathrm{O}-\mathrm{CH}_{3}\right)$ molecule, respectively, and $(\mathrm{c})$ one $\mathrm{BW} 1(\mathrm{C}=\mathrm{O})$ \& one $\mathrm{BW} 1\left(\mathrm{O}-\mathrm{CH}_{3}\right)$ molecules simultaneously for all hydrated HPxs and PMCyAs. (See Table 1 for the notations.) 

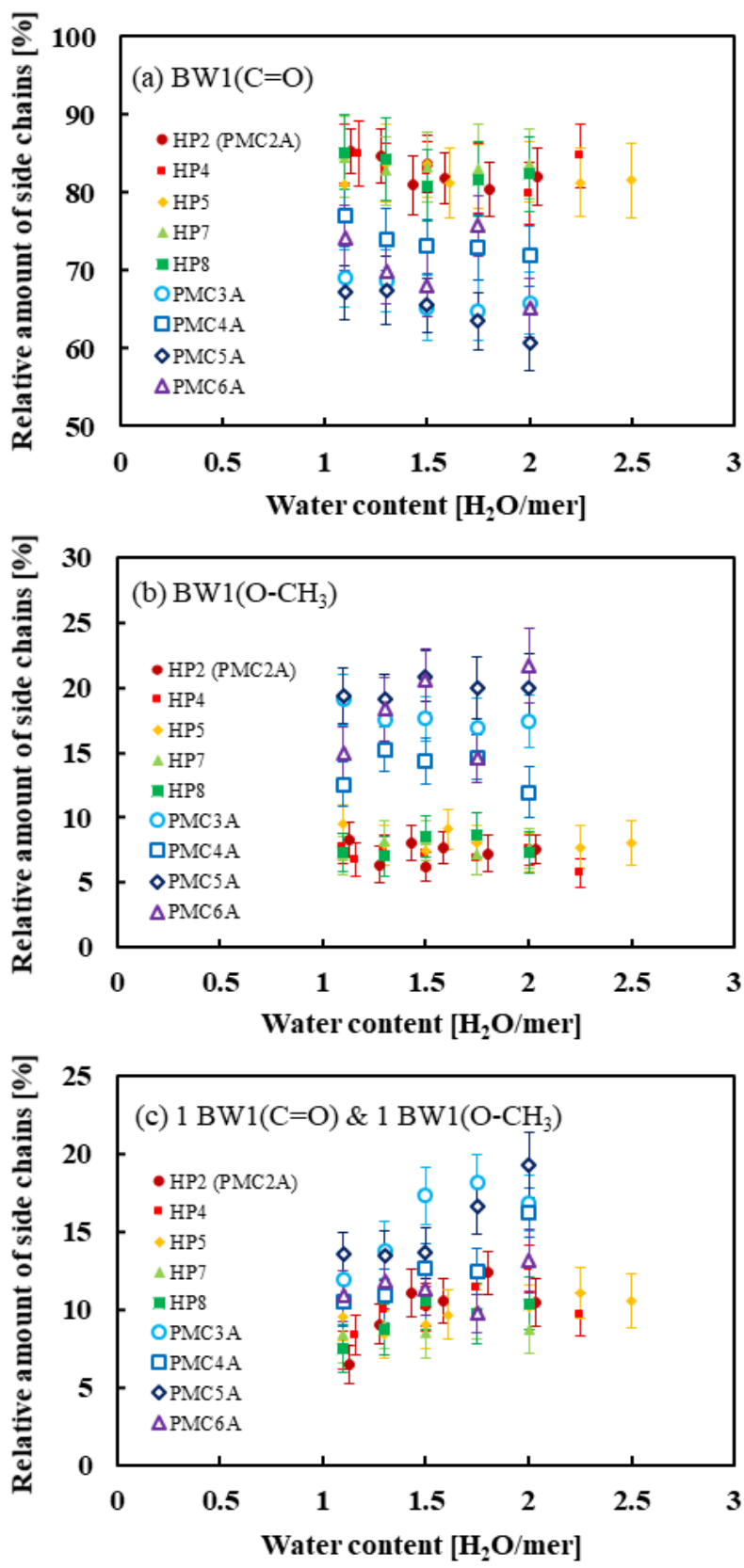

Figure S13. Relative amount of side-chains interacting with (a) one $\mathrm{BW} 1(\mathrm{C}=\mathrm{O})$ molecule, (b) one $\mathrm{BW} 1\left(\mathrm{O}-\mathrm{CH}_{3}\right)$ molecule, respectively, and (c) one $\mathrm{BW} 1(\mathrm{C}=\mathrm{O})$ \& one $\mathrm{BW} 1\left(\mathrm{O}-\mathrm{CH}_{3}\right)$ molecules simultaneously for all hydrated HPxs and PMCyAs. (See Table 1 for the notations.) 


\section{REFERENCES}

1. Kawasaki, Y.; Watanabe, H.; Uneyama, T. J. N. R. G., A note for Kohlrausch-WilliamsWatts relaxation function. Nihon Reoroji Gakkaishi 2011, 39, 127-131.

2. Sonoda, T.; Kobayashi, S.; Herai, K.; Tanaka, M., Side-Chain Spacing Control of Derivatives of Poly(2-methoxyethyl acrylate): Impact on Hydration States and Antithrombogenicity. $\quad$ Macromolecules 2020, 53, 8570-8580. DOI: 10.1021/acs.macromol.0c01144.

3. Kobayashi, S.; Wakui, M.; Iwata, Y.; Tanaka, M., Poly( $\omega$-methoxyalkyl acrylate)s: Nonthrombogenic Polymer Family with Tunable Protein Adsorption. Biomacromolecules 2017, 18, 4214-4223. DOI: 10.1021/acs.biomac.7b01247. 